\title{
ANALISIS PERBANDINGAN PERFORMA VPN IPSEC DAN ZRTP PADA VoIP
}

\author{
Muhammad Iqbal $^{1)}$, Galih Yogi Noviantoro ${ }^{2)}$, Amarudin ${ }^{3)}$ \\ ${ }^{1)}$ Teknik Komputer/ AMIK, Teknokrat-Lampung \\ ${ }^{2), 3)}$ Teknik Informatika/ STMIK, Teknokrat-Lampung \\ m.iqbal@teknokrat.ac.id ${ }^{1)}$, galihyogi1167@gmail.com²), amarudin@teknokrat.ac.id ${ }^{3)}$
}

\begin{abstract}
Abstrak - Protokol ZRTP berperan melakukan enkripsi data pada sistem komunikasi VoIP, serta adanya suatu teknologi jaringan komputer VPN IPsec dengan sistem melewatkan data dalam suatu ip private virtual atau sebagai tunnel untuk media transmisi data yang aman. Perbandingan performa pada penerapan kedua metode pengamanan data pada sistem komunikasi VoIP bertujuan untuk mengetahui protokol mana yang aman untuk diterapkan. Pada dasarnya ZRTP menggunakan pertukaran kunci Diffie-Hellman sebagai pertukaran kunci komunikasi antar client, yang mana kunci untuk komunikasi antar client tersebut menggunakan hash dari Diffie-Hellman dan dilakukan secara peer-to-peer melalui paket RTP VoIP. Sedangkan pada VPN IPsec terdapat protokol ESP (Encapsulating Security Payload) yang berfungsi sebagai enkripsi dan membuat tunnel transport RTP pada sistem komunikasi VoIP. Acuan standarisasi pengukuran kualitas VoIP yaitu rekomendasi dari ITU (International Telecomunication Union) yang merupakan standarisasi internasional untuk mengukur kualitas suara dalam komunikasi telephone. Pengujian dilakukan menggunakan variasi bandwidth 32, 64, 128, 256, 512, dan 1024 kbps. Parameter QoS (Quality of Service) yaitu delay, jitter, packet loss, dan throughput. Hasil pengujian QoS (Quality of Service) menunjukkan bahwa protokol VPN IPsec menghasilkan total delay rata-rata yang cukup rendah sebesar 69,78\% dibandingkan dengan VoIP ZRTP, throughput rata-rata yang lebih tinggi sebesar $15,53 \%$ tetapi nilai jitter cukup tinggi dibadingkan dengan ZRTP. Sedangkan packet loss pada sistem komunikasi VoIP ZRTP menghasilkan nilai packet loss yang stabil yaitu $0 \%$, sedangkan untuk VoIP VPN IPsec menghasilkan packet loss mencapai 4,62 \%.. MOS (Mean Opinion Score) menunjukan bahwa hasil perhitungan MOS Score yang menyatakan bahwa pemakaian limit bandwidth 128 kbps dan 256 kbps performa VoIP ZRTP lebih unggul sebesar 11,21\% dan 9,63\% dari performa VoIP VPN IPsec. Akan tetapi dalam pemakaian limit bandwidth 512 dan 1024 kbps performa VoIP VPN IPsec mulai mengalami peningkatan dan lebih unggul 1,18\% dan $3,23 \%$ dari performa VoIP ZRTP.
\end{abstract}

Kata Kunci-VoIP, ZRTP, VPN IPsec, QoS (Quality of Service), MOS

\section{PENDAHULUAN}

Teknologi (Voice Over Internet Protocol) VoIP merupakan teknologi yang menggunakan layanan transmisi data suara secara langsung (real time) dengan menggunakan Internet Protocol [1]. Dalam komunikasi VoIP tidak memiliki jaminan keamanan terhadap data pada komunikasi suara yang sedang berlangsung, tidak menutup kemungkinan pihak lain yang tidak berwenang melakukan penyadapan terhadap komunikasi tersebut.

Penanggulangan dari beberapa hal tersebut adalah dengan pengimplementasian metode keamanan data terhadap layanan VoIP, diantaranya dengan implementasi keamanan protokol IPSec tunneling dan ZRTP (Zimmermann Real Time Transport Protocol). IPSec (IP Security) adalah protokol yang memastikan keamanan transmisi dan autentikasi pengguna melalui jaringan, beroperasi pada network layer dari model tujuh layer OSI. Dengan menggunakan IPSec tunnel, kita dapat melakukan enkripsi atau membuat suatu jalur media komunikasi (tunnel) yang terautentifikasi [5].

ZRTP (Zimmermann Real-Time Transport Protocol) menghasilkan shared secret antara initiator dan responder yang kemudian digunakan untuk menghasilkan kunci Secure RTP (SRTP). ZRTP menggunakan pertukaran kunci Diffie-Hellman yang menegosiasikan kunci untuk mengenkripsi suara pada komunikasi VoIP. Pertukaran kunci tersebut yang akan menjaga suara atau komunikasi yang sedang berlangsung dari serangan pada komunikasi VoIP. Sehingga enkripsi yang dihasilkan adalah end to end antara pemanggil dan penerima [3] [4].

Berdasar latar belakang diatas maka penulis akan melakukan analisis performa terhadap implementasian metode pengamanan data yang berbeda untuk diterapkan pada sistem komunikasi VoIP, yaitu menggunakan ZRTP (Zimmermann Real-Time Transport Protocol) dan IPSec tunneling yang kemudian akan dianalisa keamanan data dan pengaruh yang akan timbul pada trafik kualitas suara yang dihasilkan berdasarkan pengukuran tingkat QoS (Quality of Services) dan nilai MOS (Measure Opinion Score) yang akan diperoleh [4].

\section{METODE}

\subsection{Metode Penelitian}

Penelitian ini akan dilakukan pada sebuah $P C$ yang dibangun sebagai VoIP server, satu unit router sebagai penghubung antar jaringan, satu unit switch 
sebagai sentral penghubung node jaringan, dan 3 unit laptop sebagai VoIP client. Sistem komunikasi VoIP yang akan dibangun tersebut terdapat 2 jenis, sistem komunikasi VoIP dengan metode keamanan IPsec dan ZRTP. Kemudian nantinya akan dilakukan uji performa dan keamanan terhadap data suara (voice) yang dikirim. Analisa akan dilakukan dengan membandingkan delay, jitter, packet loss, dan throughput yang dihasilkan pada VoIP IPsec dan ZRTP. Kemudian dilakukan perhitungan dan perbandingan terhadap data yang diperoleh ketika melakukan analisa dari masing-masing sistem komunikasi VoIP tersebut.

Untuk pengujian jaringan yang pertama adalah arsitektur jaringan VoIP dengan menggunakan protokol ZRTP, yang dimana implementasi dari jaringan akan menggunakan 2 buah komputer yang menggunakan softphone sebagai klien dan sebuah server VoIP dan menggunakan satu unit router sebagai pengubung dari kedua klien yang akan terkoneksi satu sama lainnya. Untuk pengujian keamanan akan disisipkan sebuah aplikasi network sniffer wireshark untuk melakukan penyadapan terhadap komunikasi yang dilakukan. Ilustrasi arsitektur VoIP yang pertama seperti Gambar 1.

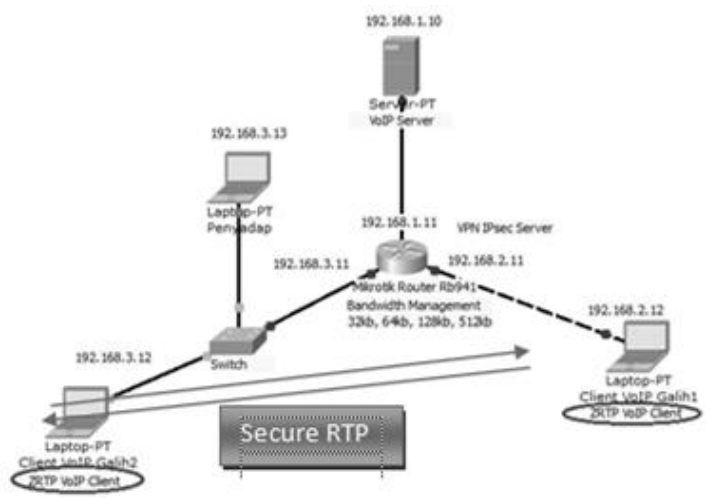

Gambar 1. Topologi Pengujian VoIP ZRTP Client

Untuk pengujian jaringan VoIP berikutnya adalah menggunakan protokol IPsec, digambarkan sebuah koneksi tunnel yang akan dibangun diantara dua buah komputer menggunakan fasilitas keamanan dari IPsec yang akan mengenkripsi komunikasi data yang terjadi diantara kedua komputer tersebut. Pada kedua komputer tersebut akan dibangun sebuah komunikasi VoIP yang menggunakan fasilitas tunnel dari IPsec. Untuk menguji keamanannya, maka akan digunakan aplikasi network analyzer untuk mencoba menangkap komunikasi yang terjadi diantara kedua komputer tersebut seperti pada Gambar 2 berikut.

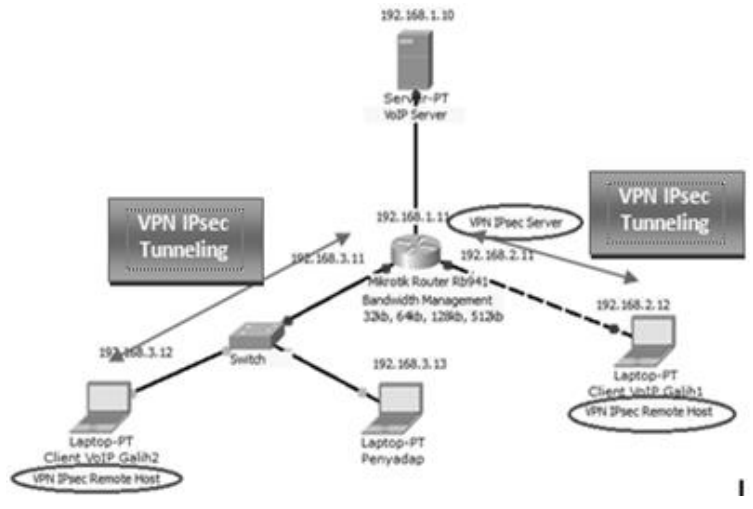

Gambar 2. Topologi Pengujian VoIP IPsec Tunneling

\section{HASIL DAN PEMBAHASAN}

\section{A. Pengujian ZRTP Pada VoIP 2 Client}

Untuk melakukan pengujian terhadap protokol ZRTP yang telah diimplementasikan pada softphone client, perlu menggunakan bantuan dari perangkat lunak network protocol analyzer seperti Wireshark. Untuk mengujinya perlu dilakukan komunikasi VoIP, bersamaan dengan diaktifkan tool Wireshark. Wireshark akan menganalisa protokol yang sedang berkomunikasi tersebut dan mencatatnya. Paket komunikasi yang menggunakan protokol ZRTP akan secara otomatis terlihat ketika komunikasi VoIP dilakukan. Selanjutnya dilakukan pengecekan terhadap komunikasi VoIP yang berhasil ditangkap oleh Wireshark. Komunikasi ini otomatis ditangkap oleh Wireshark ketika Wireshark mulai memonitor protokol yang sedang melakukan komunikasi. Hasil dari tangkapan komunikasi VoIP yang menggunakan ZRTP seperti pada Gambar 3 berikut.

\begin{tabular}{|c|c|c|c|c|c|}
\hline Source & Destination & Protocol & Length & Frame & Info \\
\hline 192.168 .2 .12 & 192.168 .2 .11 & ZRTP & & 178 Yes & Hello Packet \\
\hline 192.168 .2 .12 & 192.168 .2 .11 & ZRTP & & 178 Yes & Hello Packet \\
\hline 192.168 .2 .11 & 192.168 .2 .12 & ZRTP & & 70 Yes & HelloACK Packet \\
\hline 192.168 .2 .11 & 192.168 .2 .12 & ZRTP & & 70 Yes & HelloACK Packet \\
\hline 192.168 .2 .11 & 192.168 .2 .12 & ZRTP & & 178 Yes & Hello Packet \\
\hline 192.168 .2 .11 & 192.168 .2 .12 & ZRTP & & 178 Yes & Hello Packet \\
\hline 192.168 .2 .12 & 192.168 .2 .11 & ZRTP & & 70 Yes & HelloACK Packet \\
\hline 192.168 .2 .12 & 192.168 .2 .11 & ZRTP & & 70 Yes & HelloACK Packet \\
\hline 192.168 .2 .11 & 192.168 .2 .12 & ZRTP & & 70 Yes & Helloack Packet \\
\hline 192.168 .2 .11 & 192.168 .2 .12 & ZRTP & & 70 Yes & HelloACK Packet \\
\hline 192.168 .2 .12 & 192.168 .2 .11 & ZRTP & & 70 Yes & HelloACK Packet \\
\hline 192.168 .2 .12 & 192.168 .2 .11 & ZRTP & & 70 Yes & HelloACK Packet \\
\hline 192.168 .2 .11 & 192.168 .2 .12 & ZRTP & & 174 Yes & Commit Packet \\
\hline 192.168 .2 .11 & 192.168 .2 .12 & ZRTP & & 174 Yes & Commit Packet \\
\hline 192.168 .2 .12 & 192.168 .2 .11 & ZRTP & & 398 Yes & DHPart1 Packet \\
\hline 192.168 .2 .12 & 192.168 .2 .11 & ZRTP & & 398 Yes & DHPart1 Packet \\
\hline 192.168 .2 .12 & 192.168 .2 .11 & ZRTP & & 398 Yes & DHPart1 Packet \\
\hline
\end{tabular}

Gambar 3. Protokol ZRTP Pada Komunikasi VoIP 


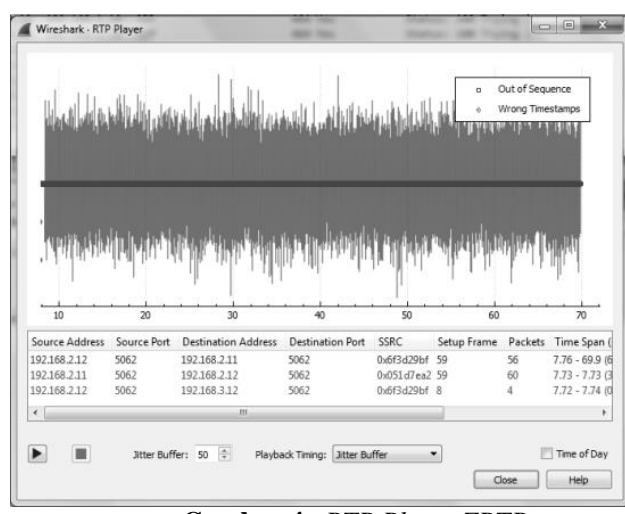

Gambar 4. RTP Player ZRTP

Setelah pendekodean dilakukan seperti pada Gambar 4 diatas, suara yang dimainkan kembali terdengan noise kasar yang menutupi isi dari komunikasi VoIP yang asli, sehingga informasi yang tersimpan pada komunikasi VoIP tersebut tidak dapat didengarkan oleh attacker.

\section{B. Pengujian IPsec Pada VoIP 2 Client}

Untuk melakukan pengecekan terhadap protokol IPsec apakah tetap berjalan melindungi komunikasi yang berlangsung, dilakukan pengecekan dengan menggunakan bantuan dari perangkat lunak Wireshark. Pada keluaran Wireshark, paket RTP yang membawa komunikasi VoIP selalu terlihat bersama dengan ESP, ini menandakan bahwa ESP yang merupakan fungsi keamanan yang disediakan oleh protokol IPsec telah berhasil mengamankan data berupa RTP yang digunakan berkomunikasi dalam uji coba komunikasi VoIP melalui tunnel IPsec seperti terlihat pada Gambar 5 berikut.

\begin{tabular}{|c|c|c|c|c|c|c|}
\hline & \multicolumn{2}{|c|}{ cosia } & \multicolumn{2}{|c|}{ 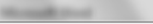 } \\
\hline Analyze Statis & tics Telephony & Wireless Tools & Help & & & \\
\hline \multicolumn{7}{|c|}{ 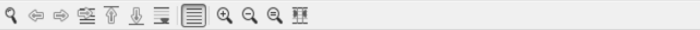 } \\
\hline Source & Destination & Protocal & Length & Frame & Info & \\
\hline 192.168 .2 .12 & 192.168 .2 .11 & ESP & & 294 Yes & & $(S P I=0 \times \theta f a b 9 d 8 b)$ \\
\hline 192.168 .2 .12 & 192.168 .2 .11 & ESP & & 294 Yes & & $(S P I=0 x e f a b 9 d 8 b)$ \\
\hline 192.168 .2 .11 & 192.168 .2 .12 & ESP & & 294 Yes & & $(\mathrm{SPI}=0 \times 49019256)$ \\
\hline 192.168 .2 .11 & 192.168 .2 .12 & ESP & & 294 Yes & & $(\mathrm{SPI}=0 \times 49019256)$ \\
\hline 192.168 .2 .12 & 192.168 .2 .11 & ESP & & 294 Yes & & (SPI=0xefab9d8b) \\
\hline 192.168 .2 .12 & 192.168 .2 .11 & ESP & & 294 Yes & & (SPI=exefab9d8b) \\
\hline 192.168 .2 .11 & 192.168 .2 .12 & ESP & & 294 Yes & & $(\mathrm{SPI}=0 \times 49019256)$ \\
\hline 192.168 .2 .11 & 192.168 .2 .12 & ESP & & 294 Yes & & $(\mathrm{SPI}=0 \times 49019256)$ \\
\hline 192.168 .2 .12 & 192.168 .2 .11 & ESP & & 294 Yes & ESP & (SPI=0xofab9d8b) \\
\hline 192.168 .2 .12 & 192.168 .2 .11 & ESP & & 294 Yes & & $(S P I=0 x \theta f a b 9 d 8 b)$ \\
\hline 192.168 .2 .11 & 192.168 .2 .12 & ESP & & 294 Yes & & $(S P I=0 \times 49019256)$ \\
\hline 192.168 .2 .11 & 192.168 .2 .12 & ESP & & 294 Yes & & $(\mathrm{SPI}=0 \times 49019256)$ \\
\hline 192.168 .2 .12 & 192.168 .2 .11 & ESP & & 166 Yes & & (SPI=exefab9d8b) \\
\hline 192.168 .2 .12 & 192.168 .2 .11 & ESP & & 166 Yes & ESP & (SPI=0xefab9d8b) \\
\hline 192.168 .2 .11 & 192.168 .2 .12 & ESP & & 182 Yes & & $(\mathrm{SPI}=0 \times 49019256)$ \\
\hline 192.168 .2 .11 & 192.168 .2 .12 & ESP & & 182 Yes & & (SPI $=0 \times 49019256)$ \\
\hline $192.168 .2 \cdot 12$ & 192.168 .2 .11 & ESP & & 294 Yes & & (SPI=exeffabgdzb) \\
\hline
\end{tabular}

Gambar 5. Paket RTP terlindungi oleh Protokol ESP

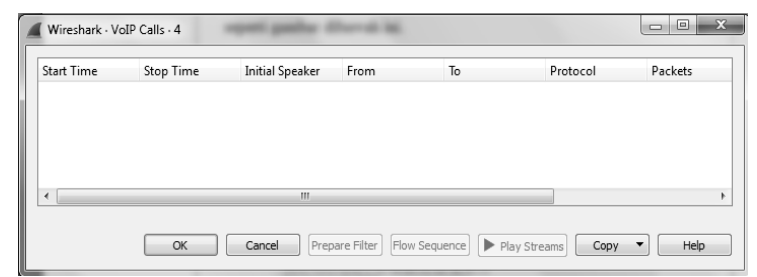

Gambar 6. Deteksi Komunikasi VoIP VPN IPsec
Pada Gambar 6 tersebut tidak ada komunikasi VoIP yang terdeteksi, jadi SIP serta RTP tidak terdeteksi pada sistem komunikasi VoIP VPN IPsec.

\section{Uji Coba Performa VoIP}

Untuk pengujian jitter, delay, packet loss, dan throughput dilakukan uji coba komunikasi sebanyak sepuluh kali dengan durasi 1 menit per komunikasi yang dilakukan oleh masing-masing jaringan VoIP, dengan variasi bandwidth 32, 64, 128, 256, 512, dan 1024 kbs, dan pada keseluruhan network dengan total pengujian dilakukan sebanyak 540 pengujian. Dalam komunikasi ini menggunakan codec G.711, baik yang menggunakan protokol ZRTP maupun VPN IPsec. Berikut merupakan delay yang diperoleh dari penerapan sistem VoIP tanpa keamanan, ZRTP, dan VPN IPsec dapat dilihat pada Tabel 1.

Tabel 1. Perbandingan delay VoIP

\begin{tabular}{l|c|c|c|c|c|c}
\hline \multicolumn{7}{c}{ Delay (ms) } \\
\hline \multirow{2}{*}{ Jenis VoIP } & \multicolumn{7}{c}{ Bandwidth } \\
\cline { 2 - 7 } & $\mathbf{3 2}$ & $\mathbf{6 4}$ & $\mathbf{1 2 8}$ & $\mathbf{2 5 6}$ & $\mathbf{5 1 2}$ & $\mathbf{1 0 2 4}$ \\
\hline VoIP & 225, & 44,5 & 26,8 & 24,0 & 20,8 & 17,9 \\
& 9 & 6 & 3 & 6 & 2 & 1 \\
\hline VoIP & 76,4 & 44,7 & 51,6 & 45,4 & 30,6 & 18,1 \\
ZRTP & 4 & 8 & & 5 & 9 & 9 \\
\hline VoIP & - & 13,3 & 10,4 & 10,1 & 11,9 & 11,7 \\
IPSEC & & 6 & & 9 & 1 & 6 \\
\hline
\end{tabular}

Pada tabel hasil pengukuran delay antara ketiga sistem komunikasi VoIP dalam pemakaian limitasi bandwidth sebesar 32, 64, 128, 256, 512, dan 1024 kbps diatas dijelaskan bahwa VoIP tanpa metode keamanan menghasilkan nilai delay sebesar 225,9 $\mathrm{ms}$ pada saat penggunaan bandwidth $32 \mathrm{kbps}$, delay tersebut termasuk dalam kategori kualitas cukup baik. Sedangkan untuk VoIP ZRTP pada bandwidth 32 dan 64 kbps protokol ZRTP tidak bisa diimplementasikan, sehingga $R T P$ paket tidak bisa diamankan dengan protokol ZRTP, protokol ZRTP berfungsi dalam minimal pemakaian bandwidth $128 \mathrm{kbps}$, dengan hasil delay sebesar 51,6 ms. Untuk VoIP VPN IPsec delay cukup stabil dibawah $14 \mathrm{~ms}$. Untuk memudahkan melihat perbandingan besar delay yang dihasilkan secara grafik dapat melihat Gambar 7 dibawah ini. Semakin kecil nilai delay atau mendekati angka nol (0) maka semakin baik kualitas voice VoIP yang dihasilkan. 


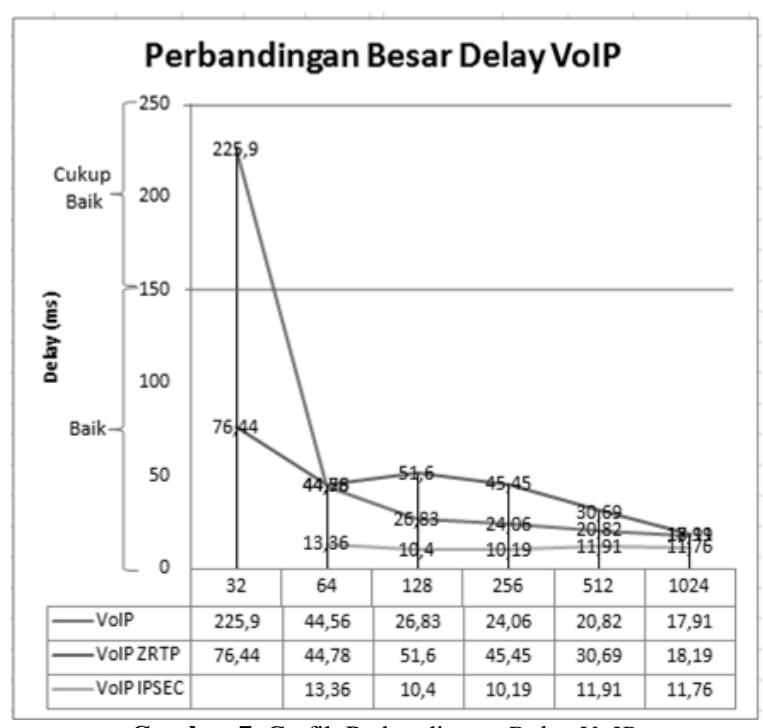

Gambar 7. Grafik Perbandingan Delay VoIP

Tabel 2 berikut merupakan besar jitter yang diperoleh dari penerapan sistem VoIP tanpa keamanan, ZRTP, dan VPN Ipsec.

Tabel 2. Perbandingan jitter VoIP

\begin{tabular}{l|c|c|c|c|c|c}
\hline \multicolumn{7}{|c}{ Jitter (ms) } \\
\hline \multirow{2}{*}{ Jenis VoIP } & \multicolumn{7}{c}{ Bandwidth } \\
\cline { 2 - 8 } & $\mathbf{3 2}$ & $\mathbf{6 4}$ & $\mathbf{1 2 8}$ & $\mathbf{2 5 6}$ & $\mathbf{5 1 2}$ & $\mathbf{1 0 2 4}$ \\
\hline VoIP & 3,78 & 1,13 & 0,91 & 1,62 & 0,98 & 0,73 \\
& & & 7 & 3 & & \\
\hline VoIP & 3,99 & 2,33 & 4,56 & 2,23 & 1,88 & 0,84 \\
ZRTP & 1 & 9 & 4 & 3 & 2 & 2 \\
\hline VoIP & - & 19,9 & 19,0 & 11,2 & 1,42 & 0,49 \\
IPSEC & & 5 & 5 & & 3 & 4 \\
\hline
\end{tabular}

Pada Tabel 2 hasil pengukuran jitter antara ketiga sistem komunikasi VoIP dalam pemakaian limitasi bandwidth sebesar 32, 64, 128, 256, 512, dan 1024 kbps diatas dijelaskan bahwa VoIP tanpa metode keamanan menghasilkan nilai jitter yang cukup kecil belum mencapai 3,8 ms, untuk VoIP ZRTP pada pemakaian bandwidth $128 \mathrm{kbps}$ protokol keamanan ZRTP sudah dapat berfungsi, dengan hasil jitter 4,564 $m s$ dan kemudian menurun sampai $0,842 \mathrm{~ms}$ pada bandwidth 1024 kbps. Unuk VoIP VPN IPsec pada pemakaian bandwidth $32 \mathrm{kbps}$ panggilan gagal dilakukan, sehingga VoIP VPN IPsec baru dapat digunakan pada limit bandwidth 64 kbps dengan hasil jitter mencapai 19,95 ms dan pada bandwidth 1024 kbps mencapai 0,494 ms. Untuk lebih jelasnya dapat dilihat pada grafik Gambar 8, semakin kecil nilai jitter atau mendekati angka nol (0) maka semakin baik kualitas voice VoIP yang dihasilkan.

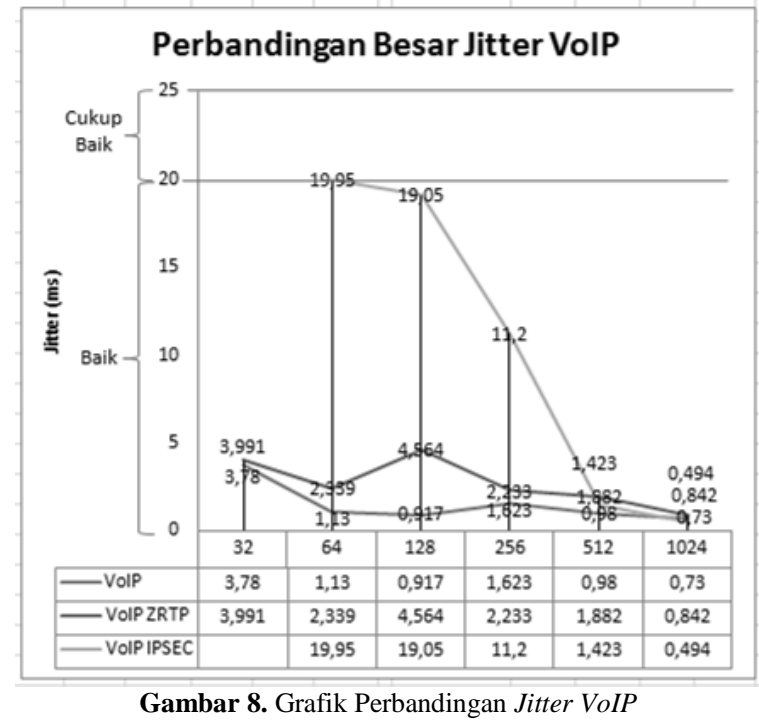

Tabel 3 berikut merupakan besar packet loss yang diperoleh dari penerapan sistem VoIP tanpa keamanan, ZRTP, dan VPN IPsec

Tabel 3. Perbandingan Packet Loss VoIP

\begin{tabular}{l|c|c|c|c|c|c}
\hline \multicolumn{7}{|c}{ Packet Loss (\%) } \\
\hline \multirow{2}{*}{ Jenis VoIP } & \multicolumn{7}{c}{ Bandwidth } \\
\cline { 2 - 8 } & $\mathbf{3 2}$ & $\mathbf{6 4}$ & $\mathbf{1 2 8}$ & $\mathbf{2 5 6}$ & $\mathbf{5 1 2}$ & $\mathbf{1 0 2 4}$ \\
\hline VoIP & 3,972 & 0,508 & 0 & 0 & 0 & 0 \\
\hline VoIP ZRTP & 0 & 0 & 0 & 0 & 0 & 0 \\
\hline VoIP IPSEC & - & 4,628 & 3,85 & 3,913 & 0 & 0 \\
\hline
\end{tabular}

Pada Tabel 3 hasil pengukuran packet loss antara ketiga sistem komunikasi VoIP dalam pemakaian limitasi bandwidth sebesar 32, 64, 128, 256, 512, dan 1024 kbps diatas dijelaskan bahwa VoIP ZRTP menghasilkan nilai packet loss yang stabil yaitu $0 \%$, sedangkan untuk VoIP VPN IPsec menghasilkan packet loss mencapai 4,62 \%. VoIP VPN IPsec baru memenuhi kategori sebagai komunikasi VoIP yang baik pada saat penggunaan bandwidth minimal 128 kbps. Untuk lebih jelas melakukan perbandingan terhadap nilai tersebut dapat kita lihat dari grafik Gambar 9 dibawah ini. Semakin kecil nilai packet loss atau mendekati angka nol (0) maka semakin baik kualitas voice VoIP yang dihasilkan. 


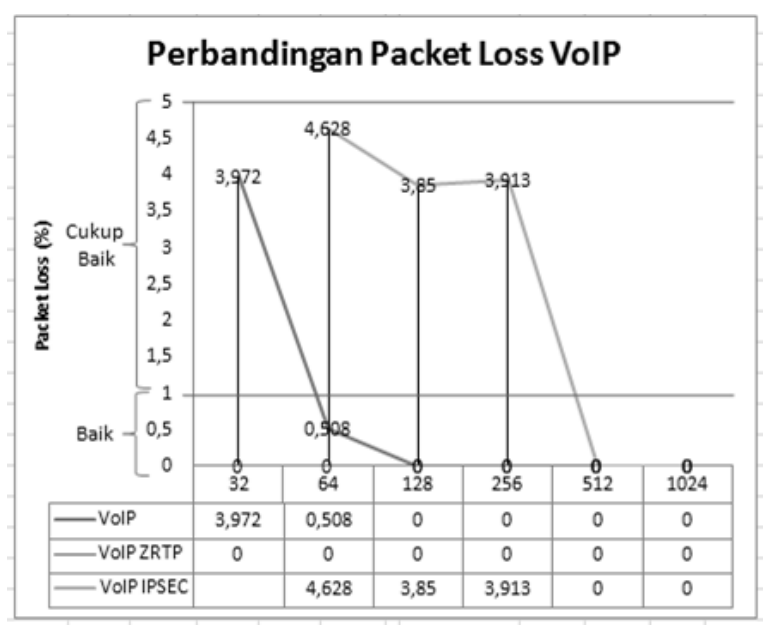

Gambar 9 Grafik Perbandingan Packte Loss VoIP

Tabel 4 berikut merupakan besar throughput yang diperoleh dari penerapan sistem VoIP tanpa keamanan, ZRTP, dan VPN IPsec

Tabel 4. Perbandingan Throughput VoIP

\begin{tabular}{l|c|c|c|c|c|c}
\hline \multicolumn{7}{c}{ Throughput (kbps) } \\
\hline \multirow{2}{*}{ Jenis VoIP } & \multicolumn{7}{c}{ Bandwidth } \\
\cline { 2 - 7 } & $\mathbf{3 2}$ & $\mathbf{6 4}$ & $\mathbf{1 2 8}$ & $\mathbf{2 5 6}$ & $\mathbf{5 1 2}$ & $\mathbf{1 0 2 4}$ \\
\hline VoIP & 160, & 164, & 219, & 272, & 269, & 284, \\
& 3 & 9 & 8 & 7 & 4 & 2 \\
\hline VoIP & 184, & 187, & 245, & 308, & 314, & 338, \\
ZRTP & 2 & 4 & 4 & 8 & 5 & 7 \\
\hline VoIP & - & 263, & 275, & 307, & 373, & 432, \\
IPSEC & & 1 & 6 & 2 & 2 & 3 \\
\hline
\end{tabular}

Pada Tabel 4 hasil pengukuran throughput antara ketiga sistem komunikasi VoIP dalam pemakaian limitasi bandwidth sebesar 32, 64, 128, 256, 512, dan 1024 kbps diatas dijelaskan bahwa pemakaian throughput terkecil terdapat pada VoIP tanpa metode keamanan, sedangkan untuk VoIP ZRTP throughput mencapai 338,7 kbps. Untuk VoIP VPN IPsec merupakan yang paling besar dalam penggunaan throughput pada range 263,1 kbps - 432,3 kbps. Nilai throughput yang semakin besar berpengaruh dalam hal konsumsi bandwidth. Untuk lebih jelas melakukan perbandingan terhadap nilai tersebut dapat kita lihat dari grafik Gambar 10 dibawah ini.

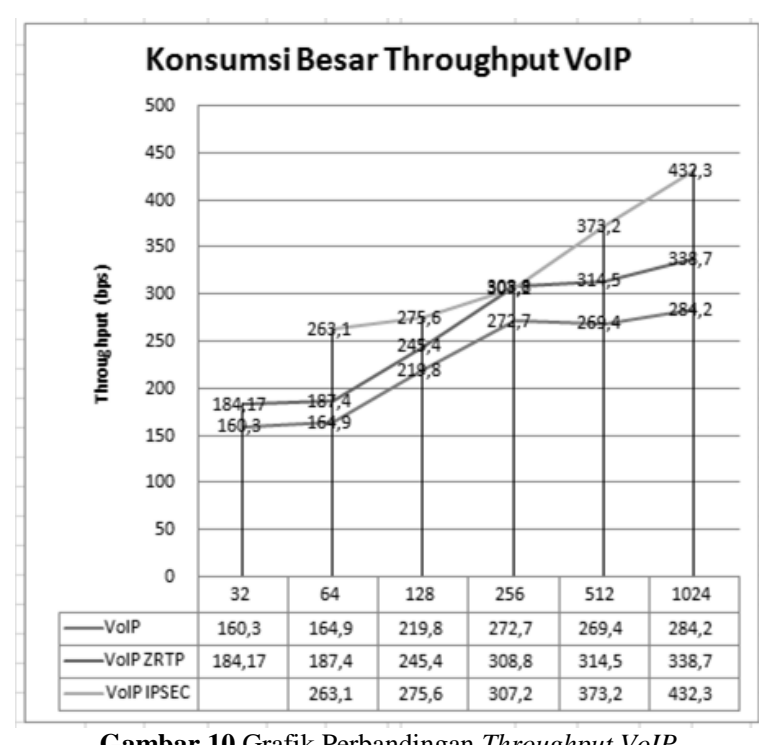

Gambar 10 Grafik Perbandingan Throughput VoIP

D. Pengukuran Kualitas VoIP Dengan MOS

Tabel 5 berikut merupakan tabel berisi besar MOS Score yang diperoleh dari penerapan sistem VoIP tanpa keamanan, ZRTP, dan VPN IPsec.

Tabel 5. Perbandingan MOS Score VoIP

\begin{tabular}{c|c|c|c|c|c|c}
\hline \multicolumn{7}{c}{ MOS SCORE } \\
\hline Bandwidth & $\mathbf{3 2}$ & $\mathbf{6 4}$ & $\mathbf{1 2 8}$ & $\mathbf{2 5 6}$ & $\mathbf{5 1 2}$ & $\mathbf{1 0 2 4}$ \\
\hline ZRTP & 4,17 & 4,19 & 4,19 & 4,14 & 4,21 & 4,23 \\
\hline VPN IPSEC & - & 3,65 & 3,72 & 3,74 & 4,26 & 4,37 \\
\hline
\end{tabular}

Pada Tabel 5 hasil perhitungan MOS antara ketiga sistem komunikasi VoIP dalam pemakaian limitasi bandwidth sebesar 32, 64, 128, 256, 512, dan 1024 kbps diatas dijelaskan bahwa kualitas VoIP tertinggi terdapat pada VoIP VPN IPsec dengan pemakaian bandwidth 1024 kbps yang menghasilkan MOS score sebesar 4,376. Untuk nilai $M O S>4,0$ merupakan sistem komunikasi VoIP dengan kualitas baik, sedangkan untuk nilai $M O S<4,0$ merupakan sistem komunikasi VoIP dengan kualitas cukup baik. Untuk nilai $M O S<3,6$ merupakan sistem komunikasi VoIP dengan kualitas kurang baik. Berikut Grafik Perbandingan MOS Score dapat dilihat pada Gambar 11. 


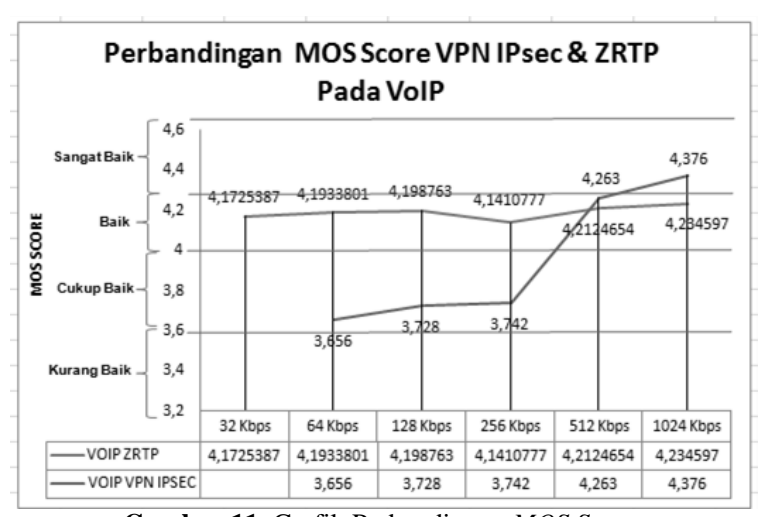

Gambar 11. Grafik Perbandingan MOS Score

\section{KESIMPULAN}

Setelah melakukan serangkaian implementasi pembangunan VoIP dan pengujian dengan skenario yang telah dijelaskan pada bab sebelumnya, maka dapat disimpulkan sebagai berikut :

1. VoIP VPN IPsec menghasilkan total delay ratarata yang cukup rendah sebesar 69,78\% dibandingkan dengan VoIP ZRTP.

2. Throughput yang berarti berpengaruh pada konsumsi bandwidth yang dipakai, dapat disimpulkan bahwa VoIP VPN IPsec menghasilkan throughput rata-rata yang lebih tinggi sebesar $15,53 \%$ dari VoIP ZRTP.

3. Perbedaan performa VoIP ZRTP dan VoIP VPN IPsec dapat dilihat pada hasil perhitungan $M O S$ Score yang menyatakan bahwa pemakaian limit bandwidth $128 \mathrm{kbps}$ dan $256 \mathrm{kbps}$ performa VoIP ZRTP lebih unggul sebesar 11,21\% dan 9,63\% dari performa VoIP VPN IPsec. Akan tetapi dalam pemakaian limit bandwidth 512 dan 1024 kbps performa VoIP VPN IPsec mulai mengalami peningkatan dan lebih unggul $1,18 \%$ dan $3,23 \%$ dari performa VoIP ZRTP.

4. Sistem komunikasi VoIP ZRTP dapat diimplementasikan dengan baik pada limit bandwidth $128 \mathrm{kbps}$, sedangkan untuk VoIP VPN IPsec baru dapat diimplementasikan dengan baik pada limit bandwidth $512 \mathrm{kbps}$.

\section{REFERENSI}

[1] Octavia, H., 2013. "Unjuk Kerja Penerapan Teknologi VoIP Pada Jaringan VPN (Virtual Private Network)", Jurnal Elektron, Vol.5 No.2 Desember. ISSN : 2085-6989.

[2] Sari, A., Brotoharsono, T., dan Purwanto, Y., 2012. "Analisis Pengaruh Penerapan IPSec Pada Implementasi Interkoneksi Ipv4-ipv6 Untuk Layanan VoIP”, Indonesia Information Security Forum IISF-2012, ISSN : 2302-4304.

[3] Yulkarnain, D., Raharjo, S., dan Lestari, U., 2013. "Perbandingan Performa Dan Keamanan VoIP Dengan Dan Tanpa VPN", Jurnal
JARKOM Vol.1 No.1 Desember 2013. ISSN : 2338-6312.

[4] Budianto, E., Rachmawati, R.Y., dan Andayanti, D., 2015. "Implementasi VoIP Menggunakan ZRTP, G.729A, Dan FreeSWITCH”, Jurnal JARKOM, Vol.3 No.1 Desember. ISSN : 23386313.

[5] Mukti, P., dkk. 2015. "Evaluasi VoIP Menggunakan Mean Opinion Score pada Jaringan Testbed-WiMAX Berbasis IEEE 802.16-2004", JNTETI Institut Teknologi Sepuluh Nopember (ITS) Vol.4 No.1 November. ISSN : 2301-4156 